ZOOLOGIA 30 (1): 101-106, February, 2013

http://dx.doi.org/10.1590/S1984-46702013000100013

\title{
A new species of Melloina (Araneae: Paratropididae) from Venezuela
}

\author{
Rogério Bertani
}

Laboratório Especial de Ecologia e Evolução, Instituto Butantan. Avenida Vital Brazil 1500, 05503-900 São Paulo, SP, Brazil.

E-mail: rbert@butantan.gov.br; rogerio.bertani@uol.com.br

\begin{abstract}
A new species of Melloina Brignoli, 1985, Melloina santuario sp. nov., is described from a cave in Venezuela. This is the third species described in this rarely sampled genus, and the first species known from both male and female. The male of M. santuario sp. nov. is distinguished by a longer embolus and fewer number of spines on the anterior tarsi. Females and immatures are distinguished by having fewer numbers of labial cuspules. The description of a new species from male and female samples increases our knowledge about Melloina. This added knowledge is important to the understanding of mygalomorph relationships, mainly in the Theraphosoidina, as Melloina is a basal genus within the Paratropididae. KEY WORDS. Cave; Glabropelma; Mygalomorphae; Neotropical; Spider taxonomy.
\end{abstract}

Melloina Brignoli, 1985 includes two rare species. The type species, Melloina gracilis (Schenkel, 1953), was described as Melloa gracilis Schenkel, 1953, based on a single male from Venezuela. It was only after 46 years that additional specimens were discovered, and a second species, Melloina rickwesti Raven, 1999, was described from a female and an immature from Panama. Meanwhile, the generic name had been changed from Melloa, preoccupied by a harvestman species, to Melloina Brignoli, 1985. The other name proposed to replace Melloa, Grablopelma Raven, 1985, was published concomitantly, but appeared shortly after BRIGNOLI's (1985) paper.

Besides being rare in collections, Melloina is of critical importance for the knowledge of mygalomorph relationships, mainly of the Theraphosoidina clade, which contains the families Theraphosidae, Barychelidae and Paratropididae (Raven 1985). RAVEN $(1985,1999)$ extensively discussed the taxonomic position of Melloina, included originally in Theraphosidae (SCHenkel 1953), and transferred by Raven (1985) to the Paratropididae. Raven (1985) showed that Melloina is a basal taxon in Paratropididae, presenting the plesiomorphic states of highly modified characters of Paratropis Simon, 1899 and related genera. Moreover, as Paratropididae is the proposed sister group of Theraphosidae (RAVEn 1985, GolobofF 1993, 1995), its most basal taxon, i.e. Melloina, retains some of the most plesiomorphic character states of Theraphosidae, the most speciose mygalomorph family. However, results of recent analyses using molecular information (HEDIN \& BOND 2006, Bond et al. 2012) conflict with the studies using morphological information, suggesting that Paratropididae is not closely related with Theraphosidae or Barychelidae. Therefore, any information on Melloina is important for the understanding of the evolution of Mygalomorphae, the Theraphosoidina, and, particularly, of Theraphosidae.
A new species of Melloina is described herein. It is the first species from this genus based on male and female specimens.

\section{MATERIAL AND METHODS}

The general description format follows RAVEN (1999, 2005), with modifications. A Nikon SMZ1500 dissecting microscope was used for illustrations (with a camera lucida attachment). Figures were digitized and covered using a Wacom Bamboo tablet. All measurements are in millimeters. Leg and palp measurements were taken from the dorsal aspect of the left side (unless appendages were lost or obviously regenerated). Measurements were taken from the drawings made with the dissecting microscope and converted. Abbreviations: (ALE) anterior lateral eyes, (AME) anterior median eyes, (ITC) inferior tarsal claw, (PLE) posterior lateral eyes, (PLS) posterior lateral spinnerets, (PME) posterior median eyes, (PMS) posterior median spinnerets, (STC) superior tarsal claws.

Specimens are deposited in the Museo del Instituto de Zoología Agrícola, Maracay, Venezuela (MIZA) and Museu Nacional, Universidade Federal do Rio de Janeiro, Rio de Janeiro, Brazil (MNRJ).

\section{TAXONOMY}

\section{Melloina Brignoli, 1985}

Melloa Schenkel, 1953: 4, f. 4a-c, type species Melloa gracilis Schenkel, 1953 by original designation; Brignoli, 1983: 138; Raven, 1985: 122, 155.

Melloina Brignoli, 1985: 380. Replacement name for Melloa Schenkel, 1953, preoccupied by Melloa Roewer, 1930 (Opiliones); Goloboff, 1993: 1-32; Raven, 1999: 819; Platnick, 2012. 
Glabropelma Raven, 1985: 70, 122, 156 f. 16-17. Superfluous replacement name for Melloa Roewer, 1930; objective synonym of Melloina; Platnick, 1989: 112; Goloboff, 1995: 1-189.

Diagnosis. See RAVen (1999).

Species included: Melloina gracilis (Schenkel, 1953), Melloina rickwesti Raven, 1999, Melloina santuario sp. nov. (Figs 1-18, Tables I-IV).

\section{Identification key to Melloina species}

\section{Males}

Male of $M$. rickwesti is unknown.

1. Male palpal bulb embolus short, less than two times the tegulum length (RAVEN 1999: fig. 2D); tarsi I-II with two rows of 9-12 spines Melloina gracilis

$1^{\prime}$. Male palpal bulb embolus long, more than three times the tegulum length (Figs 9-11); tarsi I-II with two rows of 4-5 spines (Fig. 7) .......................... Melloina santuario sp. nov.

\section{Females}

Female of $M$. gracilis is unknown.

1. Labium with $\mathrm{ca} .90$ cuspules Melloina rickwesti

1'. Labium with 46-77 cuspules (Fig. 15, Table III)..... Melloina santuario sp. nov.

\section{Melloina santuario sp. nov.}

Figs 1-18

Melloina sp.: West et al., 2008.

Diagnosis. Males of M. santuario sp. nov. can be distinguished from M. gracilis by the longer embolus (Figs 9-11) and tarsi I-II with two rows of 4-5 spines (Fig. 7). Females can be distinguished from M. rickwesti by the fewer number of cuspules on the labium (less than 80) (Fig. 15, Table III).

Type material. Male holotype (MIZA 520): VenEzUELA, Lara: near Barbacoas (El Santuario cave, $9^{\circ} 50^{\prime}$ S, $70^{\circ} 03^{\prime} \mathrm{W}$ ), 19.IV.2000, O. Villarreal leg. Paratypes: 1 female and 1 immature (MNRJ 12965) and 3 immatures (MIZA 521-523), same data and collector as holotype.

Description. Male holotype (Figs 1-13): Carapace 6.30 long, 5.24 wide, chelicerae 2.65. Leg lengths and midwidths in Table I. Abdomen 7.37 long, 3.66 wide. Spinnerets (Figs 1 and 5-6): PMS, 0.31 long, 0.13 wide, 0.01 apart; PLS, 0.72 basal, 1.04 middle, 0.82 distal; midwidths $0.49,0.49$, and 0.40 , respectively. Carapace (Figs 1 and 3): length to width 1.20; caput slightly raised, thoracic striae inconspicuous. Fovea: shallow, straight, 1.33 wide. Carapace: mostly glabrous with a few short thornlike bristles; rounded by longer stouter bristles in one row. Eyes and eye tubercle (Fig. 4): tubercle 0.24 high, length 0.83 , width 1.22. Clypeus absent. Group occupies 0.42 of head-width. Anterior row procurved, posterior slightly recurved. Sizes and inter-distances: AME 0.21, ALE 0.32, PME 0.27, PLE 0.28, AMEAME 0.1, AME-ALE 0.06, AME-PME 0.1, ALE-ALE 0.62, ALEPME 0.11, PME-PME 0.46, PME-PLE 0.04, PLE-PLE 0.87, ALE-PLE
0.07, AME-PLE 0.3. Ratio of eye group width to length 2.24 . Maxillae (Fig. 2): length to width: 1.42. Trapezoidal with conical inner edge poorly defined. Cuspules: 71 spaced, largely spread over ventral inner heel. Lyra absent. Labium: length 0.75 , width 1.13 , with 80 cuspules spaced by one diameter from each other on the anterior half center. Labio-sternal groove shallow, flat, without evident sigilla. Chelicerae (Figs 1-2): Long bristles on dorsal and anterior area, laterally with short sparse bristles. Rastellum absent, basal segments with 16 and 17 teeth on promargin, on the left and right chelicera, respectively; and a series of tiny denticles basally. Fang long. Sternum (Fig. 2): length 2.73, width 2.73. Posterior angle rounded, not separating coxae IV. Thick and longer setae near margin, fine hairs inside. Sigilla: first pair not seen, second and third hardly visible, one diameter from margin. Booklungs apertures (Fig. 5): oval and sclerotized.

Legs: formula: IV I II III. Only bristles and spines evident, cuticle not encrusted with soil. Clavate trichobothria: on central 2/4 of tarsi I-IV. Scopula: tarsi I-II with a few sparse hairs interspaced with macrosetae (Fig. 7); III-IV ascopulate (Fig. 8). Preening combs absent. Femur III very incrassate. Tarsi III, IV ventrally cracked at midpoint (Fig. 8). Spines: leg I, fe p1, d3, pa v1, ti p2, r3, v7, me p1, v15, ta v4+4 in two straight rows; leg II, fe d6, pa v1, ti p3, v9, me p2, v11, ta v5+5 in two straight rows; leg III, fe d7, pa v1, ti p2, r2, v7, me p3, r2, v11, ta v7+6 in two straight rows; leg IV, fe d8, pa v1, ti p3, r3, v7, me p2, r2, v10, ta v8+9 in two straight rows; palp fe p1, pa 0, ti p3, v6, ta 6 on larger lobe, 2 on smaller. Claws (Figs 7-8): ITC absent from all legs; STC with 4 small teeth on medial keel of leg I, 5 on II, 3 on III and IV. Teeth larger on anterior legs. Claw tufts weak but distinct on legs I, II; a few setae on legs III, IV.

Palp (Figs 9-11): bulb pyriform; embolus very long, tapering, filiform at apex; cymbium of two dissimilar lobes. Tibia with shallow distoventral groove. Spur (Figs 12-13) with two branches originating from common base, retrolateral longest, and with slight distal curvature; prolateral straight. Prolateral with ovoid spine longer than its length; retrolateral with two spines, both digitiform, more than half of branch length. Metatarsus I straight, when folded passes by retrolateral spur branch laterally. Body covering: strongly pilose hairs and guard hairs (COOKE et al. 1972) completely lacking over entire body.

Color in alcohol: carapace and legs red brown. Abdomen dorsally gray with 3 faint pallid lenticular areas anteriorly, followed by three pairs of small spots; pallid ventrally.

Female paratype (Figs 14-17): Carapace 6.12 long, 4.57 wide, chelicerae 3.11. Leg lengths and midwidths in Table II. Abdomen 9.50 long, 4.97 wide. Spinnerets: PMS, 0.45 long, 0.17 wide, 0.17 apart; PLS, 0.8 basal, 0.71 middle, 0.96 distal; midwidths $0.5,0.5$, and 0.47 , respectively.

Carapace (Fig. 14): length to width 1.34; caput slightly raised, thoracic striae inconspicuous. Fovea: shallow, straight, 0.87 wide. Carapace: mostly glabrous with a few short thornlike bristles; rounded by longer stouter bristles in one row. Anterior 

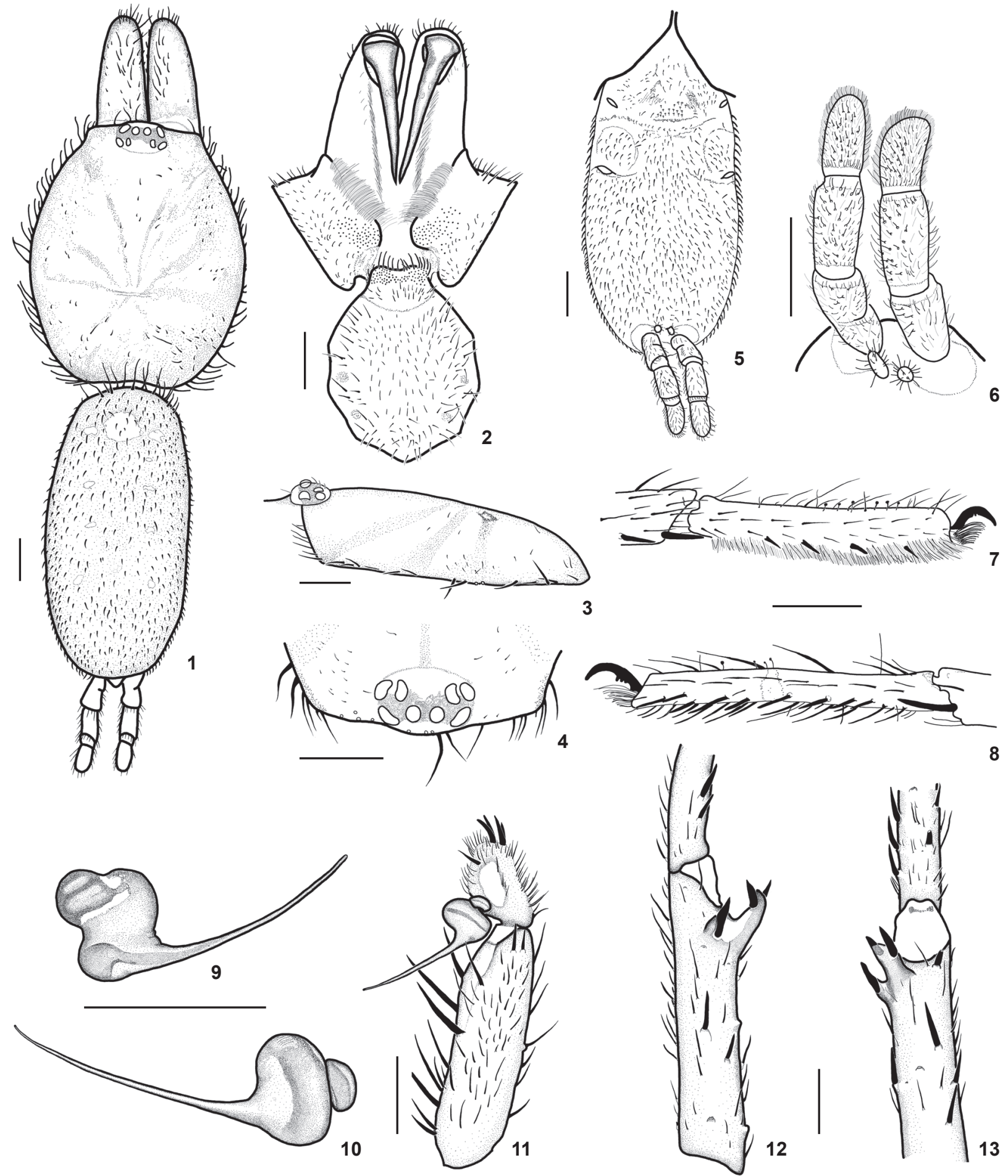

Figures 1-13. Melloina santuario sp. nov., holotype male: (1) cephalothorax and abdomen, dorsal; (2) sternum, maxillae and labium; (3) carapace and eye tubercle, lateral; (4) eye tubercle, dorsal; (5) abdomen, ventral; (6) spinnerets, ventral; (7) left leg I tarsus, prolateral; (8) left leg IV tarsus, retrolateral; (9-10) left male bulb; (9) prolateral; (10) retrolateral; (11) left male palp, retrolateral; (12-13) left leg I spur; (12) prolateral; (13) ventral. Scale bar: $1 \mathrm{~mm}$. 


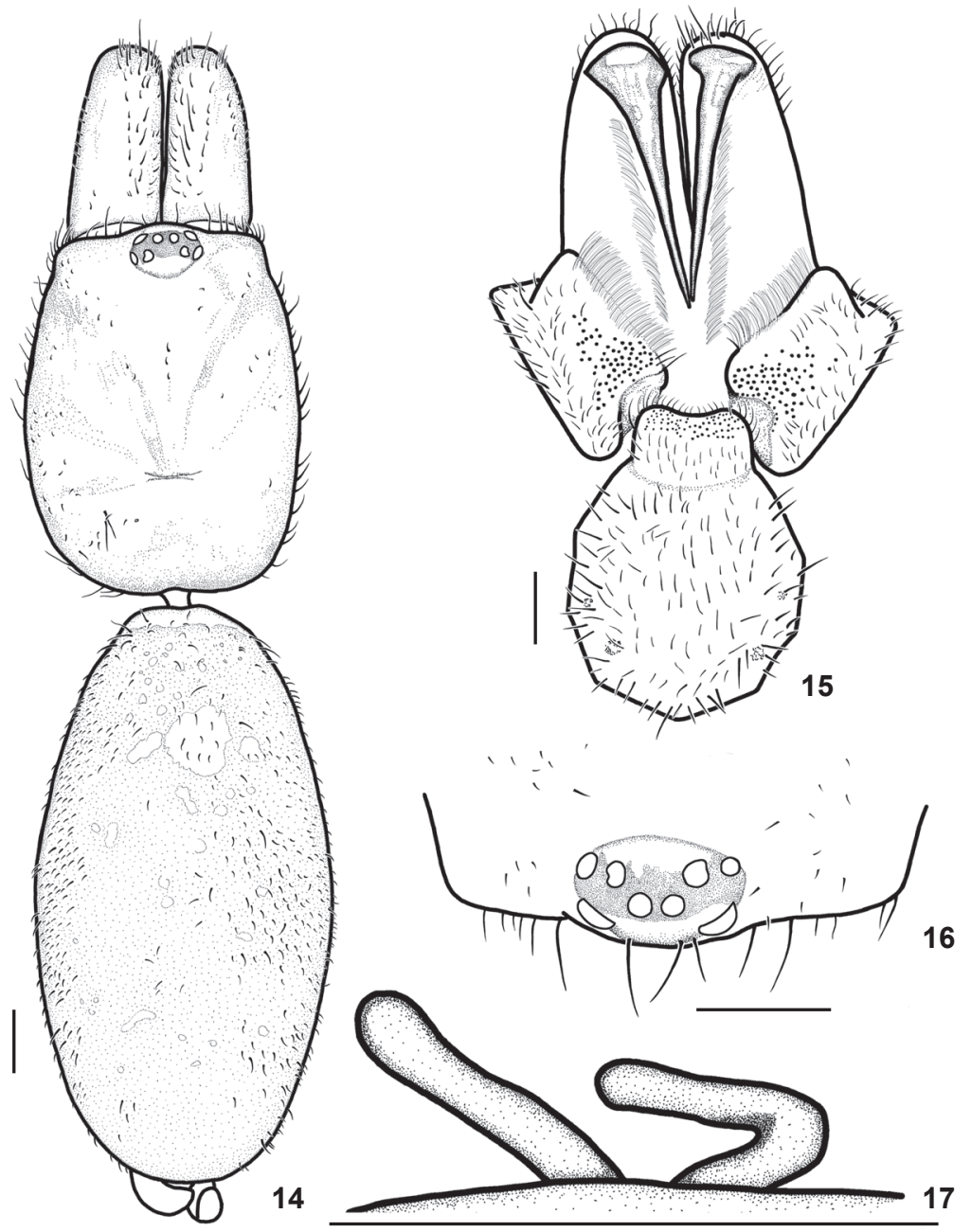

Figures 14-17. Melloina santuario sp. nov., paratype female: (14) cephalothorax and abdomen, dorsal; (15) sternum, maxillae and labium; (16) eye tubercle, dorsal; (17) spermathecae, ventral. Scale bar: $1 \mathrm{~mm}$.

lateral thorax with encrusted soil patches on both sides. Eyes and eye tubercle (Fig. 16): tubercle 0.23 high, length 0.79 , width 1.23. Clypeus absent. Group occupies 0.35 of head-width. Anterior row procurved, posterior slightly recurved. Sizes and interdistances: AME 0.16, ALE 0.36, PME 0.2, PLE 0.25, AME-AME 0.11, AME-ALE 0.14, AME-PME 0.11, ALE-ALE 0.6, ALE-PME 0.21, PME-PME 0.45, PME-PLE 0.08, PLE-PLE 0.9, ALE-PLE 0.1, AMEPLE 0.34. Ratio of eye group width to length 2.13. Maxillae (Fig. 15): length to width: 1.44 . Trapezoidal with conical inner edge not well defined. Cuspules: 90 spaced, largely spread over ventral inner heel. Lyra absent. Labium: length 0.83 , width 1.37 , with 77 cuspules spaced by one diameter from each other on the anterior half center. Labio-sternal groove shallow, flat, without evident sigilla. Chelicerae (Fig. 15): long bristles on dorsal and anterior area, laterally with short sparse bristles. Rastellum absent, basal segments with 16 and 15 teeth on promargin, on

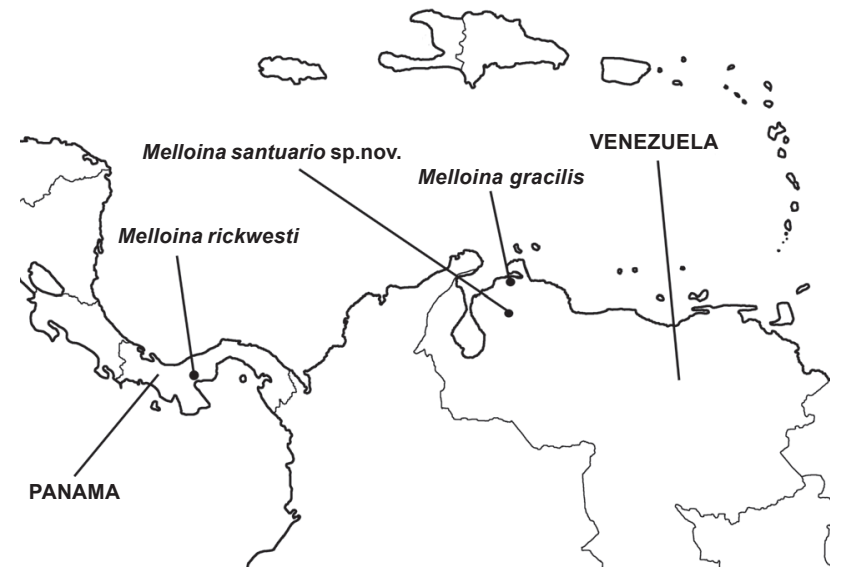

Figure 18. Records of Melloina species. 
Table I. Melloina santuario sp. nov., male holotype. Length and midwidths of right legs and palpal segments.

\begin{tabular}{ccccccc}
\hline Length / Midwidths & Femur & Patella & Tibia & Metatarsus & Tarsus & Total (length) \\
\hline Pp & $3.01 / 0.84$ & $2.08 / 0.74$ & $2.74 / 0.80$ & - & $0.92 / 0.60$ & 8.75 \\
I & $5.37 / 1.16$ & $3.19 / 1.04$ & $4.52 / 0.97$ & $4.17 / 0.61$ & $2.79 / 0.44$ & 20.04 \\
II & $4.60 / 1.05$ & $2.65 / 0.97$ & $3.48 / 0.80$ & $3.43 / 0.54$ & $2.54 / 0.43$ & 16.70 \\
III & $4.06 / 1.39$ & $2.34 / 0.91$ & $3.16 / 0.81$ & $4.04 / 0.53$ & $2.60 / 0.38$ & 16.20 \\
IV & $5.93 / 1.20$ & $2.82 / 1.01$ & $5.09 / 0.80$ & $6.38 / 0.51$ & $3.54 / 0.36$ & 23.76 \\
\hline
\end{tabular}

Table II. Melloina santuario sp. nov. Female paratype. Length and midwidths of right legs and palpal segments.

\begin{tabular}{ccccccc}
\hline Length / Midwidths & Femur & Patella & Tibia & Metatarsus & Tarsus & Total (length) \\
\hline Pp & $3.02 / 0.77$ & $1.88 / 0.86$ & $2.36 / 0.77$ & - & $2.11 / 0.57$ & 9.37 \\
I & $4.61 / 1.02$ & $2.86 / 0.93$ & $3.63 / 0.87$ & $2.53 / 0.51$ & $2.20 / 0.54$ & 15.83 \\
II & $3.93 / 0.99$ & $2.46 / 0.84$ & $3.00 / 0.71$ & $2.61 / 0.50$ & $2.15 / 0.43$ & 14.15 \\
III & $3.30 / 1.14$ & $2.08 / 0.84$ & $2.64 / 0.78$ & $2.88 / 0.56$ & $2.17 / 0.44$ & 13.07 \\
IV & $5.25 / 1.01$ & $2.65 / 0.94$ & $4.47 / 0.74$ & $5.17 / 0.55$ & $2.76 / 0.40$ & 20.30 \\
\hline
\end{tabular}

Table III. Melloina santuario sp. nov. Cuspules of maxillae and labium.

\begin{tabular}{|c|c|c|c|c|c|}
\hline \multirow{2}{*}{ Collection number } & \multirow{2}{*}{ Sex } & \multirow{2}{*}{ Carapace length/width } & \multicolumn{3}{|c|}{ Cuspules on } \\
\hline & & & Left maxilla & Right maxilla & Labium \\
\hline MIZA 520 & Male & $6.30 / 5.24$ & 71 & 71 & 80 \\
\hline MNRJ 12965 & Female & $6.12 / 4.57$ & 82 & 90 & 77 \\
\hline MNRJ 12965 & Immature male & $5.28 / 4.20$ & 73 & 67 & 56 \\
\hline MIZA 521 & Immature male & $5.75 / 4.47$ & 67 & 68 & 61 \\
\hline MIZA 522 & Immature male & $4.43 / 3.56$ & 54 & 60 & 61 \\
\hline MIZA 523 & Immature male & 3.49 / 2.94 & 41 & 33 & 46 \\
\hline
\end{tabular}

Table IV. Melloina santuario sp. nov., spines on tarsi.

\begin{tabular}{clcccccc}
\hline Collection number & \multicolumn{1}{c}{ Sex } & Carapace length/width & Palp & Leg I & Leg II & Leg III & Leg IV \\
\hline MIZA 520 & Male & $6.30 / 5.24$ & 8 & $4+4$ & $5+5$ & $6+7$ & $8+9$ \\
MNRJ 12965 & Female & $6.12 / 4.57$ & 11 & $4+5$ & $5+6$ & $10+6$ & $9+7$ \\
MNRJ 12965 & Immature male & $5.28 / 4.2$ & 11 & $4+4$ & $5+5$ & $6+7$ & $7+10$ \\
MIZA 521 & Immature male & $5.75 / 4.47$ & 13 & $4+4$ & $5+5$ & $6+7$ & $7+7$ \\
MIZA 522 & Immature male & $4.43 / 3.56$ & 9 & $4+4$ & $5+5$ & $6+7$ & $6+6$ \\
MIZA 523 & Immature male & $3.49 / 2.94$ & 9 & $3+4$ & $4+5$ & $5+8$ & $5+5$ \\
\hline
\end{tabular}

the left and right chelicera, respectively; and a series of tiny denticles basally. Fang long. Sternum (Fig. 15): length 2.68, width 2.65. Posterior angle rounded, not separating coxae IV. Thick and longer setae near margin, fine hairs inside. Sigilla: first pair not seen, second and third hardly visible, one diameter from margin. Booklungs apertures: oval and sclerotized.

Legs: formulla: IV I II III. Only bristles and spines evident, cuticle not encrusted with soil. Clavate trichobothria: on central 2/4 of tarsi I-IV. Scopula: tarsi I-IV ascopulate. Preening combs absent. Tarsus IV ventrally cracked at midpoint. Spines: leg I, fe $\mathrm{d} 1$, pa 0 , ti v2, me v8, ta v4+5 in two straight rows; leg II, fe d1, pa 0 , ti p1, v3, me p1, v8, ta v5+6 in two straight rows; leg III, fe $\mathrm{d} 5$, pa 0 , ti p1, v7, me p3, r2, v10, ta v10+6 in two straight rows; leg IV, fe d4, r1, pa 0, ti p2, r3, v3, me p2, r2, v9, ta v9+7 in two straight rows; palp fe p1, pa 0 , ti 0 , ta v11. Claws: ITC absent from all legs; STC with 2 small teeth on medial keel of leg I, 4 on II-IV. Palp with single claw lacking tooth. Claw tufts weak but distinct on legs I, II; a few setae on legs III, IV. 
Spermathecae (Fig. 17): two long, separated lobes. Body covering: strongly pilose hairs and guard hairs (Сооке et al. 1972) completely lacking over entire body.

Color in alcohol: carapace and legs red brown. Abdomen dorsally gray with 3 faint pallid lenticular larger areas and several smaller ones anteriorly; pallid ventrally.

Distribution. Only known from type locality (Fig. 18).

Etymology. Name in apposition after the type-locality, the cave "El Santuario", Lara, Venezuela.

\section{DISCUSSION}

According to Raven (1999), M. rickwesti is distinguished from M. gracilis by having "only two rows each of four spines on ventral tarsi (cf. 9-12), only tarsi IV (cf. III and IV) cracked, and a relatively shorter sternum and larger labium". The difference was considered "greater than that found between male and female conspecific paratropidines in a pending revision of the sister subfamily" (RAVEN 1999). In the present work, I was able to confirm that the number of tarsal spines, mainly on tarsi I and II (Table IV), is similar in mature males, females, and immature males. Therefore, the greater number of tarsal spines in M. gracilis is an autapomorphy of the species. The other two characters are, unexpectedly, sexually dimorphic. Mature males of M. santuario sp. nov. have tarsi III and IV cracked, whereas females and immature males have only tarsus IV cracked. Females and immature males of $M$. santuario sp. nov. have a larger labium than mature males, and the shape of their labium is similar with females of M. rickwesti.

Paratropidids are normally found with the entire body encrusted with soil (RAVEN 1985, 1999) due to their habit of hiding in the surface layers of the soil (WEST in RAVEN 1999). However, in all analyzed specimens of M. santuario sp. nov., the integument is not encrusted with soil, except for very restricted areas on the carapace of the female paratype.

\section{ACKNOWLEDGMENTS}

I thank Jose Clavijo, O. Villarreal and Adriano Kury for specimen loans and two anonymous reviewers for improving the manuscript.

\section{LITERATURE CITED}

Bond, J.E.; B.E. Hendrixson; C.A. Hamilton \& M. Hedin. 2012. A Reconsideration of the Classification of the Spider Infraorder
Mygalomorphae (Arachnida: Araneae) Based on Three Nuclear Genes and Morphology. PLoS ONE 7(6): e38753. doi:10.1371/journal.pone.0038753.

Brignoli, P.M. 1983. A catalogue of the Araneae described between 1940 and 1981. Manchester, Manchester University Press, 755p.

BRIGNOLI, P.M. 1985. On some generic homonymies in spiders. Bulletin of the British Arachnological Society 6: 380 .

CоOKE, J.A.L.; V.D. Roth \& F.H. Miller. 1972. The urticating hairs of theraphosid spiders. American Museum Novitates 2498: 1-43.

Goloboff, P.A. 1993. A reanalysis of mygalomorph spider families (Araneae). American Museum Novitates 3056: 1-32.

Goloboff, P.A. 1995. A revision of the South American spiders of the family Nemesiidae (Araneae, Mygalomorphae). Part I: species from Peru, Chile, Argentina, and Uruguay. Bulletin of the American Museum of Natural History 224: 1-189.

Hedin, M. \& J.E. Bond. 2006. Molecular phylogenetics of the spider infraorder Mygalomorphae using nuclear rRNA genes (18S and 28S): Conflict and agreement with the current system of classification. Molecular Phylogenetics and Evolution 41: 454-471.

PlatNICK, N.I. 1989. Advances in Spider Taxonomy 1981-1987: A supplement to Brignoli's A catalog of the Araneae described between 1940 and 1981. Manchester, Manchester University Press, $846 \mathrm{p}$.

Platnick, N.I. 2012. The world spider catalog version 12.5. American Museum of Natural History. Available online at: http://research.amnh.org/iz/spiders/catalog. DOI:10.5531/ db.iz.0001. [Accessed: 9.V.2012]

Raven, R.J. 1985. The spider infraorder Mygalomorphae (Araneae): Cladistics and systematics. Bulletin of the American Museum of Natural History 182: 1-180.

Raven, R.J. 1999. Review of the mygalomorph genus Melloina Brignoli (Paratropididae: Araneae). Memoirs of the Queensland Museum 43 (2): 819-825.

RAVEN, R.J. 2005. A new tarantula species from northern Australia (Araneae, Theraphosidae). Zootaxa 1004: 15-28.

SCHENKEl, E. 1953. Bericht über einige Spinnentiere aus Venezuela. Verhandlungen der Naturforschenden Gesselschaft in Basel 65: 1-57.

West, R.C.; S.D. Marshall; C.S. Fukushima \& R. Bertani. 2008. Review and cladistic analysis of the Neotropical tarantula genus Ephebopus Simon 1892 (Araneae: Theraphosidae) with notes on the Aviculariinae. Zootaxa 1849: 35-58.

Submitted: 06.VI.2012; Accepted: 21.VII.2012.

Editorial responsibility: Gabriel L.F. Mejdalani 